kaolinisation of the felspar in each ton of rock would require to elevate it to an extent it would be difficult to estimate.

To this Mr. Church, who derives his heat from the hydration of silicate of aluminium during the formation of kaolin, objects that the whole of the alkalies liberated by the decomposition of felspar do not become dissolved in water, and that their amount cannot cunsequently be taken as a measure of the quantities of that mineral which have been decomposed.

In support of this argument he states that clays from the immediate neighbourhood of the Comstock lode still contain above $4 \frac{1}{2}$ per cent. of alkalies, and ignores the fact that the final result of kaolinisation is the production of a hydrated silicate of aluminium free from alkalies. The clays in question must consequently be regarded as containing undecomposed felspar which cannot have contributed to any increase of temperature.

Admitting 'however for the sake of argument that all the felspar has been decomposed, and that three-fourths of the alkalies present have been retained by the resulting clay, the heat corresponding to the decomposition and hydration of the felspars in a ton of rock must be reduced by three-fourths. If, therefore, as before, to simplify our ideas, we regard the heat required to produce the observed effects as due to a single variation of temperature, the original temperature must have been above twenty times higher than the melting point of gold, which appears as improbable as that found on the assumption of the whole of the alkalies entering into solution.

The assumption now made, namely, that much of the kaolinisation of the felspar is accomplished by aqueous vapour which is entirely absorbed by the rock, and which does not give rise to any aqueous solutions, involves conditions of which we have no known example, and of which it is difficult to conceive the existence at such great depths below the water-level of the country.

This view of the question was not advanced by $\mathrm{Mr}$. Church in his original paper of 1878 , and has probably occurred to him subsequently to the publication of my observations in the Quarterly Fournal of the Geological Society in the following year. If however the possibility of such an alteration were admitted, it certainly could not be ascribed to kaolinisation, since the removal of the alkalies in felspars is an essential factor in that transformation.

With regard to the hot spring which formerly issued from between slate rocks and an elvan dyke at Wheal Clifford Mine in Cornwall containing notable quantities of chloride of lithium and other alkaline salts, cited by $\mathrm{Mr}$. Church in his recent pamphlet in support of his views with respect to kaolinisation, the effect has probably been taken for the cause. Hot water is known to be a better solvent of mineral matter than cold water, and it has been shown by Daubrée that at ligh temperatures and under great pressure it is even capable of rapidly dissolving silica out of glass, and of leaving it in the form of crystallised quartz.

We have no direct evidence that the dissociation of the constituents of felspar and the subsequent hydration of the clay produced give rise to any liberation of heat. It is well known that the temperature of mines situated in granite, where kaolinisation is constantly going on, is lower than that of those worked in clay-slate, while high temperatures or thermal springs are not more frequently observed in masses of kaolinised granite than elsewhere.

The mines on the Comstock lode are situated in a highly volcanic region of very late tertiary age, and in the almost immediate vicinity of lava-flows and boiling springs. Until, therefore, stronger evidence than that yet furnished shall have been brought forward, it is probable that the majority of geologists may continue to ascribe these phenomena to the action of volcanic agencies. J. ARThuR PhILlips

18, Fopstone Road, Kensington, S.W., August 9

\section{British Museum Attendants}

As you are a free lance in British Museum matters, will you not make some remarks on the attendants? They are, as a body, intelligent and desirous of learning, but no attempts seem ever to be made to instruct them in the subjects of their departments; and all the information they possess is picked up by scraps, from overhearing the remarks of their chiefs to distinguished visitors.

Many of them do what they can to teach themselves; but why should they not have some regular training, and be competent to give simple and informal description-lectures to parties who really go for instruction? It cannot be said that it would imperil their charges by occupying their attention, when we see how a far scantier supply of care-takers completely guard South Kensington.

The object is not to get a higher paid and superior class of men, but to give them the advantages they might reasonably enjoy, and use them as rational beings. I have heard some of them deplore the way in which they are treated, "like so many watch-dogs"; the snuff-taking to keep awake; the lapses of the stouter ones into afternoon naps; the forbidden conversations, even on the objects of their care, with visitors; the reading of all the advertisements of the Times, for lack of better interest; all these are familiar subjects, as you will find if you once tap the flow of forbidden talk successfully.

Some attention to them might prevent such a colloquy as I once had with a flashy-looking fellow on one of the many unlabelled objects in his department. I asked, "Do you know where that squared block is from that stands on that terminal ornament?" Gallio (with a flower in his button-hole): "Which do you mean?" "That one which has another rough block standing on it." Gallio (impatiently): "Well! what about it?" "Do you know where it came from?" Gallio (with ineffable contempt): "No! indeed; I don't know where it's from. I don't know anything about it." If you should care to quote this, I can vouch for its accuracy, as I noted it at the time. Bromley, Kent WM. Flinders PETrie

\section{Quassia and Mosquitos}

In Nature, vol. xxii. p. Ir, I read a letter in which the employment of a wash made from a decoction of quassia wood was recommended as a protection from the attacks of mosquitos and other insect pests. After reading the above-named letter I sent some of the quassia to my son, who is a surveyor camping out on the prairie in Dakotah Territory, U.S.A., in a part much infested in hot weather by mosquitos. In a recent letter my son states that he has repeatedly tried the wash with quassia, but without any beneficial results, the mosquitos having attacked him even before the solution had dried on his skin.

I have suggested that he should try carbolic acid ointment, if he can procure any, as English insects do not like the carbolic odour.

Possibly the mosquitos referred to in your correspondent's letter may have been much better fed than the North American tormentors.

If any of your numerous readers could communicate some effectual protection against the attacks of these pests, it would be a great boon to those who suffer so much from them. Manchester, August 9 J. B. DANCER

\section{Fascination}

A VERY simple explanation may be offered of the seemingly mysterious facts of fascination, whether in man or the lower animals. Every one knows the old and ludicrous problem requiring us to decide what would happen to a hungry donkey placed at a spot exactly equidistant from two quite equally attractive bundles of hay. In theory the creature starves, being unable to make up its mind to choose one bundle rather than the other without any reason for such choice. In practice it is generally supposed that the unsteadiness of this world's affairs would speedily destroy the equilibrium of motives and leave the donkey free to make its meal of one or other of the bundles. But in critical emergencies, such as those mentioned in $\mathrm{Mr}$. Curran's letter, when shot and shell are flying rapidly towards their victims, almost instantaneous decision is necessary. The circumstances are such that movement either to the right or to the left would be equally salutary and efficacious, but for the very reason that one movement would be just as good as the other, the mind makes its fatal pause of indecision. A man standing in the path of an advancing express train, and a small bird eyed by a snake, are probably affected both in the same manner. There need be no occult isfluence in the eye of the basilisk, as there can be no magical power in the iron and brass of the steam-engine, to transfix and fascinate the prey. Terror may no doubt in some instances paralyse the brain and make it incapable of choosing the method of escape, which to an intellect unembarrassed and free from panic would be the one obviously worthy of choice, but in the military examples cited by $\mathrm{Mr}$. Curran it would be indecent to suggest such an explanation of the facts, and needless when the simpler solution is available.

Tunbridge Wells, August 9 Thomas R. R. STEBBING 